\title{
Fabrication and Characterization of Starch-Based Biodegradable Polymer with Polyvinyl Alcohol
}

\author{
Shanta Pokhrel*, Lalita Sundari Rai \\ Department of Chemistry, Tri-Chandra Multiple Campus, Tribhuvan University, Kathmandu, Nepal \\ *Corresponding E-mail: shantabhattarai2014@gmail.com \\ (Received: Sept. 18, 2019; Revised: Dec. 24, 2019 \& Accepted: Dec. 26, 2019)
}

\begin{abstract}
Starch is a renewable, biodegradable and low-cost natural biopolymer with high availability. Starch was extracted from Solanum tuberosum (potatoes) and its preliminary properties were studied. The structure of extracted starch was characterized by Fourier Transform Infrared Spectroscopy (FTIR) and Scanning Electron Microscopy (SEM). A series of starch-based biodegradable blends, with polyvinyl alcohol (PVA) were prepared by using glycerol as a plasticizer and citric acid as a crosslinking agent, through solution casting method and their biodegradable properties were studied. The structure of the blend was characterized by Fourier Transform Infrared Spectroscopy (FTIR) and Differential Scanning Calorimeter (DSC). The morphology of starch shows the potato starch has oval or ellipsoid in the structure having a size of 20-35 $\mu \mathrm{m}$. The compatibility of the two components can be improved by the hydroxyl group present on both starch and PVA. As compared to pure polyvinyl, the melting point of the blend was decreased. The blends were found degradable within a weak.
\end{abstract}

Keywords: Biodegradable, DSC, starch, polyvinyl alcohol, PVA/starch blend.

\section{Introduction}

The plastic we used in our daily life is easy to use, inexpensive, flexible as well as durable. But they are chemically synthesized from petrochemical industries and produced with huge toxic additives. They are non-renewable, non-degradable and lack of infrastructure [1,2]. Being non-degradable they cause white pollution and reduce the resources. The preparation of biodegradable plastic is a wise thought to overcome these problems, which can be prepared from agricultural products [3].

Solanum tuberosum is the third major source of starch [4]. It is naturally occurring agricultural residue and renewable which can be used to produce degradable plastic [5]. Pure starch has low water resistibility, processability, thermal stability, and strength. To overcome these fallacies starch is often blended with other degradable $e^{\varepsilon}$ polymers such as polylactic acid (PLA), poly--caprolactone (PCL), polyvinyl alcohol (PVA) $[2,3,6]$. PVA is semicrystalline, non-toxic, water-soluble, having excellent optical and physical properties [7]. The blend of PVA and starch still lacks some mechanical and thermal properties [2]. So, glycerol and citric acid (CA) can be used as a plasticizer and crosslinking agent respectively $[8,9]$.

Several kinds of research have been conducted on the biodegradation of starch, PVA and starch -blends. Starch can be readily metabolized by a range of microorganisms to fermentation products such as ethanol [10,11], hydrogen $[12,13]$ and methane [14]. PVA is also susceptible to biological degradation, however, the process was slow [15]. Furthermore, the overall number of PVA degrading microorganisms was rather limited in comparison to the widespread species able to degrade aliphatic polyesters, such as polyhydroxyalkanoate (PHA) and PLA [16].

Chen et al., observed that the rates of biodegradation in starch-PVA cast films were degraded much faster than pure PVA [17]. Mao et al. in his work reported that the addition of PVA slowed the degradation process in the samples [9]. Russo et al. investigated the degradability of thermoplastic starch and PVA blends under anaerobic conditions and concluded that predominantly PVA remained at the end and that 
starch was almost entirely degraded [18]. Chai et al. evaluated the biodegradability of modified starchPVA blends with bio-reactivity kinetic models. And conclude, the degradability of PVA was enhanced with the addition of the starch [19]. Cinelli et al. characterized the biodegradability with or without a cross-linking agent of PVA, starch, and lignocellulosic films. Results were in favor of biodegradation [20].

Tang; Zou et al. done their studied the biodegradability of nano-SiO 2 reinforced starch/PVA nanocomposite films. Results showed that nanoparticles had no significant influence on the biodegradability of films [21]. Popescu et al. researched the degradation of clay-starch-PVA nanocomposite films and concluded that the biodegradation of films depended on both type and content of nanoparticles and the nanoparticles hindered the rate of biodegradation [22].

Starch-PVA films can be chosen for the biomedical and clinical field (such as drug control release carrier and biomembrane) [23], while chemically bonded composites can be taken as recyclable sizing agents [24]. PVA/starch has been considered for the replacement of polystyrene foams for expanded foams as loose-fill packaging materials.

According to Vilpoux and Avérous, the commercial alternative to polystyrene (PS) is a blend with $95 \%$ of hydroxyl propylated high amylose starch and $5 \%$ of PVA [25]. PVA/starch blends are sensitive to moisture but they are good in providing barriers to oxygen and carbon dioxide. So they can act as flavor and aroma barriers, having good resistance to most organic compounds and solvents can be used in food technology [2]. Although there are several kinds of research have done on fabrication and characterization of PVA/starch film with the mechanical test, still there is a lack of research on thermal properties and complete biodegradation. Hence this work is a step further to study thermal behavior and biodegradation of PVA/starch blends.

\section{Materials and Methods}

\section{Materials}

Solanum tuberosum were collected from National Potato Research Project (NPRP), Khumaltar, Lalitpur in the month of June 2018, they were cultivated in Parwanipur, Bara district and harvested in March and stored in cold store of NPRP, Lalitpur. Polyvinyl alcohol, glycerol, citric acid were brought from Thermo Fisher Scientific India Pvt. Ltd. (India). The water used in the whole thesis work was de-ionized water brought from the local shop of Kathmandu.

\section{Extraction of starch from Solanum tuberosum}

The process of extraction of starch from Solanum tuberosum was done according to Singh and Singh [26]. The tubers of Solanum tuberosum was cleaned properly, peeled off and cut into small pieces and were dipped in water containing a small amount of potassium metabisulfite $\left(\mathrm{K}_{2} \mathrm{~S}_{2} \mathrm{O}_{5}\right)$. Then grinned and filtered, the residue was washed with distilled water and left for decantation. After complete decantation, the starch cake was collected and dried at a temperature of $40{ }^{\circ} \mathrm{C}$ in a hot-air cabinet drier.

\section{Preparation of PVA/starch blends}

The fabrication of starch with PVA was done by following the protocol mentioned by Shi et al. via the solution casting process [23]. The solution was prepared by dissolving the PVA, starch, and glycerol in hot water at $95{ }^{\circ} \mathrm{C}$ to form a homogeneous gellike solution then citric acid was added into the mixture with a mechanical stirrer for 10 minutes at $30{ }^{\circ} \mathrm{C}$. Bubbles were removed with an aspirator. The prepared solution was poured on a pre-warmed glass Petri-plate and evaporated from the molds at $25^{\circ} \mathrm{C}$ for one week. The dried films were sealed in polyethylene bags and were stored at $20^{\circ} \mathrm{C}$ to characterize them.

\section{Characterization}

\section{Characterization of extracted starch}

\section{Moisture content}

The determination of moisture content of starch follows the AOAC process [27]. The crucible and lid were dried in the oven at $105{ }^{\circ} \mathrm{C}$ for 3 hours and transferred to desiccator to cool. Weighed it out. Weighed $3 \mathrm{~g}$ starch sample was spread uniformly in the crucible. Then the crucible was placed in an oven for 3 hours at $105{ }^{\circ} \mathrm{C}$. After that, it was transferred to desiccator with the partially covered lid to cool. Reweighted the dish and starch sample. For this, three concurrent data was taken and the mean value was found then moisture content was calculated by the following equation (i). 


$$
\begin{aligned}
& \text { Moisture }(\%)=\frac{\left(\mathrm{W}_{1}-\mathrm{W}_{2}\right)}{\mathrm{W}_{1}} \times 100 \% \text {----(i) } \\
& \text { Where, } \mathrm{W}_{1}=\text { weight of sample before drying in gram. } \\
& \qquad \mathrm{W}_{2}=\text { weight of sample after drying in gram. }
\end{aligned}
$$

\section{Ash content}

To determine the ash content of the starch AOAC method was followed [27]. The crucible and lid were placed in the furnace at $550{ }^{\circ} \mathrm{C}$ overnight. The crucible was cooled in a desiccator for 20 minutes. The crucible and lid were weighed to decimal places. The starch sample was weighed and put into the crucible. The crucible was heated over low Bunsen flame with half covered. When flames were no longer produced, crucible with lid was placed in the furnace. It was heated at $550{ }^{\circ} \mathrm{C}$ overnight. During heating, the crucible was not covered by a lid. The lid was placed on crucible after complete heating, to prevent loss of fluffy ash. Then it was placed in desiccator to cool down. The ash with crucible and lid was weighed. And the ash content was calculated by the following equation (ii).

$$
\text { Ash }(\%)=\frac{\text { weight of ash }}{\text { weight of sample }} \times 100 \%
$$

\section{Amylose content}

A starch sample of $0.10 \mathrm{~g}$ was weighed into $100 \mathrm{~cm}^{3}$ volumetric flask and $1 \mathrm{~cm}^{3}$ of $99 \%$ ethanol and 9 $\mathrm{cm}^{3}$ of $1 \mathrm{M}$ sodium hydroxide $(\mathrm{NaOH})$ solution were carefully added. The contents were mixed thoroughly and the sample solution was heated for 10 mins in boiling water to gelatinize the starch. After cooling the solution was made up to the mark with distilled water and shaken thoroughly. $5 \mathrm{~cm}^{3}$ of starch solution in a $100 \mathrm{~cm}^{3}$ volumetric flask was treated with $1.0 \mathrm{~cm}^{3}$ of $1 \mathrm{M}$ acetic acid and $2.0 \mathrm{~cm}^{3}$ of iodine solution. The solution was diluted to the mark with distilled water and absorption was read using a spectrophotometer at $620 \mathrm{~nm}$. The absorbance of a blank solution prepared accordingly was subtracted from that of the sample and amylose and amylopectin contents were calculated using equations (iii) respectively.

$$
\text { Amylose content }(\%)=3.06 \times \text { absorbance } \times 20 \% \ldots
$$

\section{Fourier transform infrared (FTIR) spectroscopy}

The FTIR analysis for starch samples was done in the Nepal Academy of Science and Technology
(NAST), Khumaltar, Lalitpur by using SHIMADZU spectrophotometer (IR Prestige-21) Nepal. The spectra were obtained at a resolution range of 400 $\mathrm{cm}^{-1}$ to $4000 \mathrm{~cm}^{-1}$.

\section{Scanning electron micrograph (SEM)}

For surface morphology, starch samples were dehydrated in $99.8 \%$ ethanol and sprinkled on carbon tape mounted on an aluminum stub. Then they were coated with a thin gold film using a sputter coater and observed in a FEGSEMMAIA3 (model 2016) microscope (Tescan, Czech Republic) at an accelerating potential of $2 \mathrm{kV}$.

\section{Characterization of PVA/starch blends}

\section{Fourier transform infrared (FTIR) spectroscopy}

FTIR analysis for PVA/starch blends was done by IRTracer-100, SHIMADZU in the Central Department of Chemistry, Tribhuvan University, Kritipur, Kathmandu, Nepal. The sample was prepared by mixing the fine powder with $\mathrm{KBr}$ and pressing. The spectra were obtained at a resolution range of 400 $\mathrm{cm}^{-1}$ to $4000 \mathrm{~cm}^{-1}$.

\section{Differential scanning calorimeter (DSC)}

Differential scanning calorimetry thermograms were recorded by NETZSCH DSC 204 F1 phoenix (India) instrument. Sample pieces of about $10 \mathrm{~g}$ were placed in an aluminum pan and were first cooled to room temperature and held there for $5 \mathrm{~min}$. After that, a heating scan was conducted from $25{ }^{\circ} \mathrm{C}$ to $250{ }^{\circ} \mathrm{C}$ at a heating rate $10 \mathrm{~K} / \mathrm{min}$.

\section{Biodegradation test of PVA/starch blends}

Here the process of Azahari et al. was performed for the process of biodegradation test of PVA/starch blends [28]. The biodegradation test was performed under compost burial conditions. One vase of the approximate capacity of $5 \mathrm{~L}$ was filled with cow's dung compost. The composites were cut into $2 \mathrm{~cm} \times$ $2 \mathrm{~cm}$ in square shape and each sample was enclosed in tea bags individually and made. The samples were buried in the compost at a depth of $10 \mathrm{~cm}$ and the moisture of the compost was maintained by sprinkling water at regular intervals of time.

The degradation of the samples was determined at regular intervals of 7 days by carefully removing the sample from the compost and washing it gently with 
ethanol to remove the trace of compost from the film and dried in an oven at $60{ }^{\circ} \mathrm{C}$ for 4 hours and weight of the samples were taken on a digital balance.

\section{Results and Discussion}

\section{Yield of starch}

The yield of starch from the tuber of Solanum tuberosum was calculated using the standard equation, on the basis of the mass of raw Solanum tuberosum sample of starting material. Using raw Solanum tuberosum sample as reference the yield of starch was found to be $3.82 \%$ in Khumal Rato (KR).

The yield of starch was found affected by various artificial factors including wet storage [29], genetic variation [30,31], the drying conditions of the raw materials (oven-dried chips and flour have higher yield than sun-dried ones) [32], harvesting time and root storage (root storage decreased starch content) $[33,34]$, the form of the roots used for extraction (fresh root gave better extraction efficiency and purer starch than dried chips and pellets) [35], and the environmental conditions for growing the crop (e.g., two growth locations gave significant difference in the starch yield of the same variety) [30]. Thus for high starch yield, varieties with high dry matter content and thin peel thickness are suitable [36]. All these factors can be controlled, and careful selection of the parameters would lead to a maximum of starch yield. It should be noted that high yield does not necessarily mean the starch would have the desired quality for any specific application.

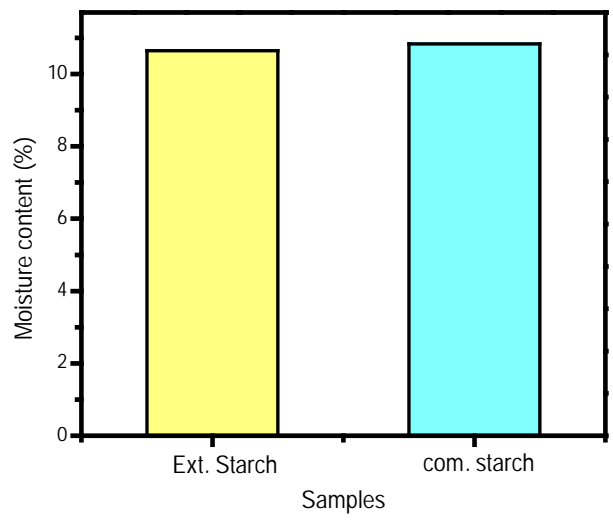

Figure 1: Moisture content of extracted starch and commercial starch.

The moisture content of extracted starch from Khumal Rato and commercial starch is represented in Figure 1.
The result showed that the moisture content of Khumal Rato was $10.65 \%$ and commercial starch was $10.84 \%$. The relatively low moisture content of the starches makes them easy to store at room temperature and less prone to colonization by organism degradation as shown for root, tuber and cereal starches [37,38] making them suitable for utilization in industries like the filler in biodegradable plastic and pharmaceutical industry that make use of low moisture content. The range of moisture contents in these starches varied from 7.54 to $9.37 \%$. Tapioca starch showed slightly lower moisture content $(7.54 \%)$ than corn starch $(7.74 \%)$ and similar to the results of on mango starch [39]. Potato starch had a significantly higher moisture level $(9.37 \%)$ than other starches.

Ash content of extracted starch and commercial starch is shown in Figure 2. From the graph, the ash content of the starch from the Khumal Rato was $0.7 \%$ and commercial starch was 0.8 . However, the ash content of the potato was significantly higher than 0.20 to $0.22 \%$ for Oat starches [40]. The ash content is an estimate of the total mineral content of the starch. The low ash content is an indication of the good quality of the starches, because high mineral content is sometimes used to retard the growth of certain microorganisms [36].

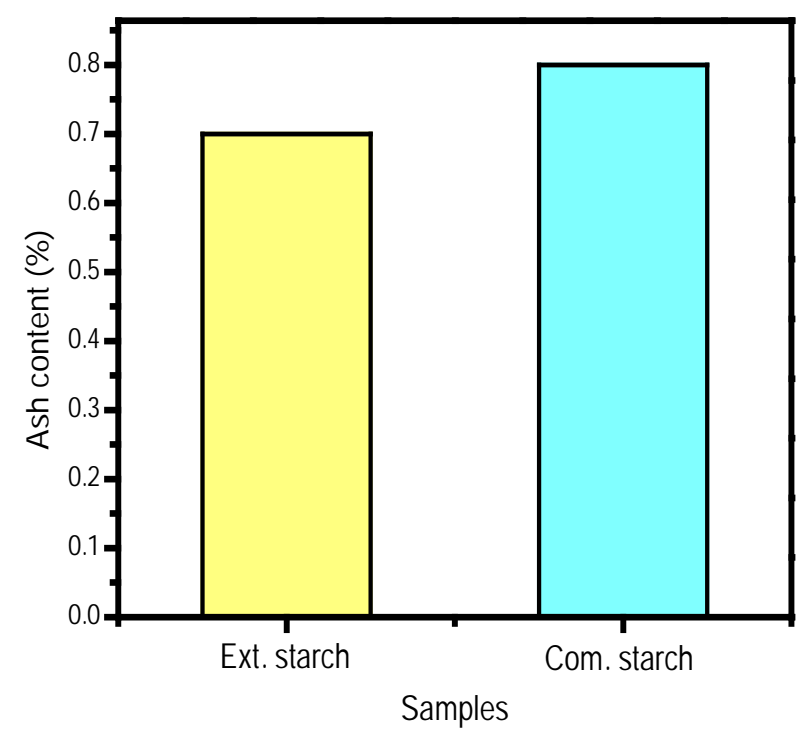

Figure 2: Ash content of extracted starch and commercial starch.

The amylose content of starch determines its properties (such as water-binding capacity, thickening, gelling, etc.) and as a result dictates most of its uses. The 
results obtained showed significant variations. The amylose contents (in terms of amylose equivalent) for extracted starches from Khumal Rato was found to be $23.26 \%$, higher than values reported for mango [39] and corn starches 16.9-25.3\% [41] and also higher than that of oat [40] and of tapioca (16.27\%). These values were slightly higher than those reported by Glicksman and Rapaille and Vanhemelrijck for potato (22\%) starch, but comparable to that for corn (26\%) and tapioca (17\%) starches. Thus, the starch could be applied in industries that produce, fillers, thickeners, binders, etc.[42].

Xia et al., reported that the structure of amylose is sensitive to physical and chemical treatments. When slight applied of heat change the amount of content.

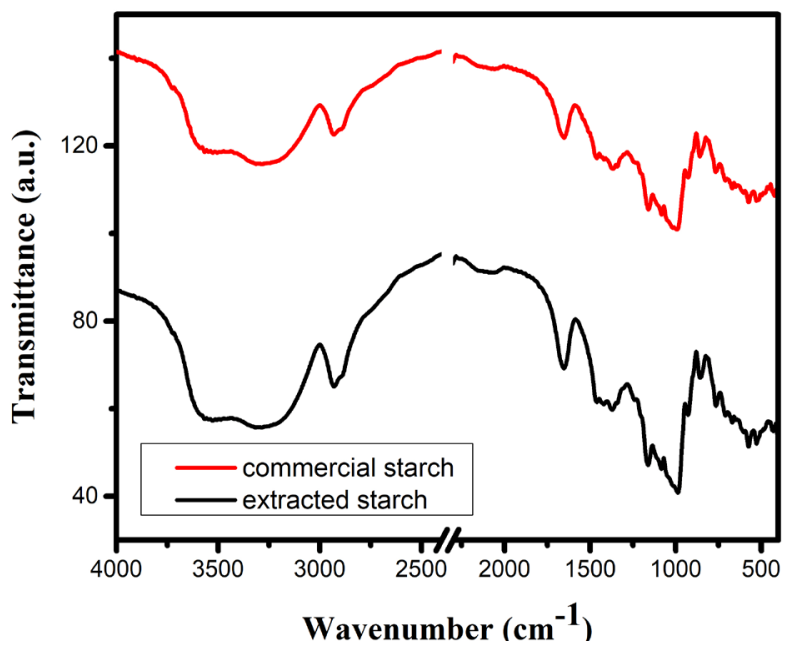

Figure 3: FTIR spectra of extracted starch and commercial starch.

The FTIR spectra of extracted starch and commercial starch are presented in Figure 3, whereas the interpretation of each peak is given in Table 1 .

As shown in the graph, the presence of an absorption band at around $3600-3300 \mathrm{~cm}^{-1}$ for both starch is due to the vibration of the hydroxyl groups $(-\mathrm{OH})$. The band at $2927 \mathrm{~cm}^{-1}$ is the characteristic peak of the $\mathrm{C}-\mathrm{H}$ stretching vibration of the amylase and amylopectin, present in starch. The peak occurred for extracted starch at $1645 \mathrm{~cm}^{-1}$ is due to the tightly bound water molecules. The changes in the crystallinity of the starch are reflected around this band. The band at $1157 \mathrm{~cm}^{-1}$ of extracted starch and commercial starch is assigned as a complex mode involving the $\mathrm{CH}_{2} \mathrm{OH}$ side chain in amylase.
In addition, the characteristic C-O-C ring vibration on starch leads to an absorbance peak at around 700-900 $\mathrm{cm}^{-1}$. The $\mathrm{C}-\mathrm{O}$ bending associated with the $\mathrm{OH}$ group would cause an absorbance peak at around $1648 \mathrm{~cm}^{-}$ 1. Furthermore, the absorbance peak at $1419 \mathrm{~cm}^{-1}$ implied the presence of $\mathrm{C}-\mathrm{H}$ symmetrical scissoring of $\mathrm{CH}_{2} \mathrm{OH}$ moiety. The uncommon $\mathrm{CO}_{2}$ peak in starch $\left(2358 \mathrm{~cm}^{-1}\right)$ was observed in the potato starch IR spectrum. It might result from measuring conditions [43].

SEM is used to investigate the granule morphology of the potato starch. The morphology of starch was shown in Figures 4 and 5.

Table 1: Band assignment of potato starch.

\begin{tabular}{llll}
\hline S. No. & \multicolumn{1}{c}{ Functional group } & $\begin{array}{c}\text { Wave number } \\
\mathrm{cm}^{-1}\end{array}$ & \multicolumn{1}{c}{$\begin{array}{c}\text { Potato starch } \\
\mathrm{cm}^{-1}\end{array}$} \\
\hline 1 & O-H stretching & $3600-3300$ & $3569-3170$ \\
2 & C-H stretching & 2931 & 2931 \\
3 & C-O bending associated with & 1637 & 1645 \\
& OH group & & \\
4 & $\mathrm{CH}_{2}$ symmetric deformation & 1458 & 1437 \\
5 & $\mathrm{CH}_{2}$ symmetric scissoring & 1415 & 1419 \\
6 & $\mathrm{C}-\mathrm{H}$ symmetric bending & $1385-1375$ & 1381 \\
7 & $\mathrm{C}-\mathrm{O}-\mathrm{C}$ asymmetric stretching & 1149 & 1157 \\
8 & C-O stretching & $1200-800$ & 993 \\
9 & C-O-C ring vibration of & 920,$856 ; 758$ & $929,858,763$ \\
& carbohydrate & & \\
\hline
\end{tabular}

The starch image has 20 and 50 resolutions. The image revealed that the potato starch granules exits in smooth granule form have oval and ellipsoid shapes with sizes ranging from 5 to $35 \mu \mathrm{m}$ in width and 15 to $60 \mu \mathrm{m}$ in height.

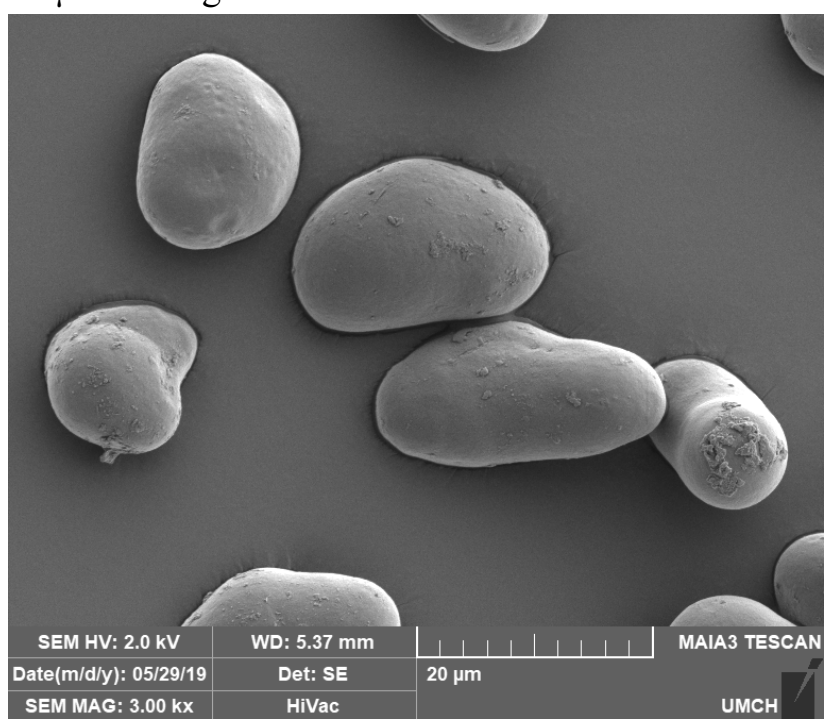

Figure 4: SEM image of potato starch having $20 \mu \mathrm{m}$ resolution. 


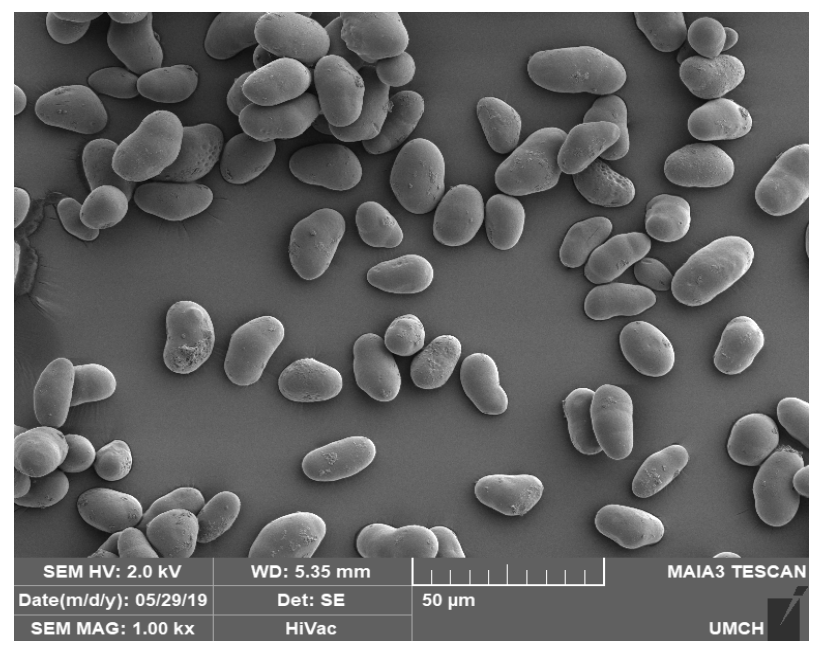

Figure 5: SEM image of the potato starch powder having $50 \mu \mathrm{m}$ resolution.

Wang reported in his work, the sizes of small and large granules ranged from 0.4 to $3 \mu \mathrm{m}$ and from 6 to $40 \mu \mathrm{m}$ in maize starch, from $0.6 \mu \mathrm{m}$ and from 10 to $100 \mu \mathrm{m}$ in potato starch, and from 0.6 to $6 \mu \mathrm{m}$ and from 10 to $70 \mu \mathrm{m}$ in pea starch, respectively. Fannon et al. mentioned that SEM has been used to relate granule morphology to starch genotype. Svegmark and Hermanson reported that the variation in size and shape of starch granules is due to the biological origin. Singh and Singh claimed that the morphology of granules depends on the biochemistry of chloroplast or amyloplast and physiology of plants [44].

\section{Characterization of PVA/starch blends}

The fabricated starch/PVA blends were transparent, flexible, are characterized via FTIR, DSC and biodegradation test.

The FTIR spectra of PVA/starch blends with different content of PVA shown in Figure 6 and band assignment is shown in Table 2.

Broad and strong absorption band from 3200-3600 $\mathrm{cm}^{-1}$ is the cause of the stretching vibration of $-\mathrm{OH}$ present in starch. The absorption band $2931 \mathrm{~cm}^{-1}$ is due to an aliphatic saturated $\mathrm{C}-\mathrm{H}$ stretching vibration of starch.

Another absorption band at $1640 \mathrm{~cm}^{-1}$ is because of the stretching vibration of $\mathrm{C}=\mathrm{O}$ and at $1651 \mathrm{~cm}^{-1}$ is due to the bending mode of the absorbed water and some contribution from the carboxylate group. The vibration of the $\mathrm{CH}_{2}$ group produces an absorption

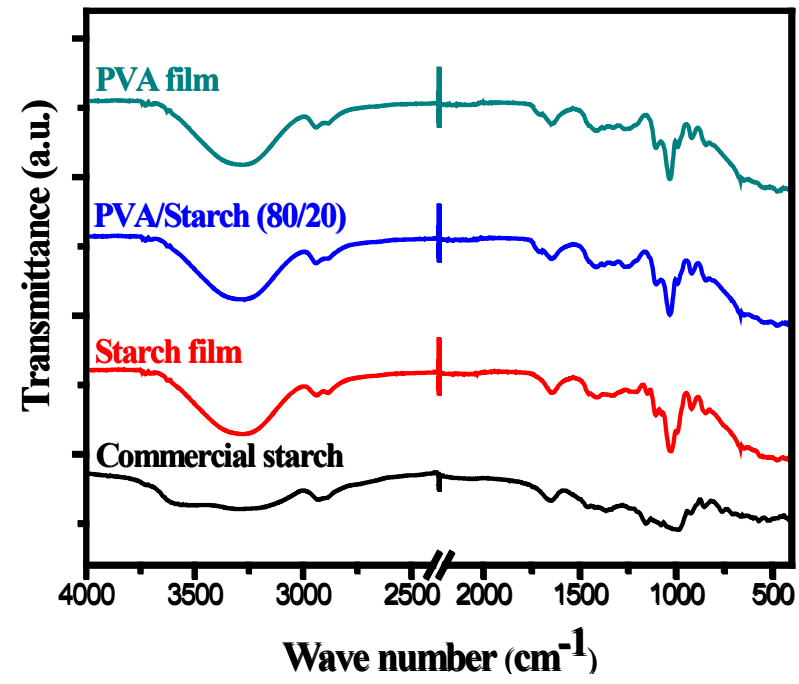

Figure 6: FTIR spectra of commercial starch and PVA/ starch blends

band at $1409 \mathrm{~cm}^{-1}$. Due to the cause of C-O stretching an absorption band at $1035 \mathrm{~cm}^{-1}$ was produced.

Blout et al., reported that a peak at $2361 \mathrm{~cm}^{-1}$ is due to atmospheric carbon dioxide. Peaks due to water in the films occur at $1652 \mathrm{~cm}^{-1}$ and around $3240 \mathrm{~cm}^{-1}$. The later peak overlaps the peak due to the $-\mathrm{OH}$ stretching of hydroxyl groups.

Table 2: Characteristics FTIR bands starch/PVA blend.

\begin{tabular}{llll}
\hline S.N. & $\begin{array}{c}\text { Functional group } \\
{[\mathbf{3 , 8}]}\end{array}$ & $\begin{array}{c}\text { Wave number }\left(\mathbf{c m}^{-}\right. \\
\mathbf{1})[\mathbf{3 , 8}]\end{array}$ & \multicolumn{1}{c}{ Blends } \\
\hline 1 & $-\mathrm{OH}$ stretching & $3600-3200$ & 3285 \\
2 & $\mathrm{C}-\mathrm{H}$ & $3000-2850$ & 2931 \\
5 & $\mathrm{C}-\mathrm{C}$ & 1636 & 1640 \\
6 & $\mathrm{CH}_{2}$ & $1461-1417$ & 1409 \\
8 & $\mathrm{C}-\mathrm{O}$ & $1141-1093$ & 1035 \\
9 & $\mathrm{C}-\mathrm{O}-\mathrm{H}$ & 669 & 652 \\
\hline
\end{tabular}

Another research by Finch et al., mention that peaks at 2912, 1324 and 843 and $1084 \mathrm{~cm}^{-1}$ are attributed to the $\mathrm{C}-\mathrm{H}$ stretching, $\mathrm{C}-\mathrm{H}$ bending and $\mathrm{C}-\mathrm{O}$ stretching of PVA, respectively. The broad high absorption peak at $3237 \mathrm{~cm}^{-1}$ is assumed to arise from the $-\mathrm{OH}$ stretching frequencies of PVA and water hydroxyl groups. The band at $1708 \mathrm{~cm}^{-1}$ was attributed to the carbonyl functional groups due to residual acetate groups remaining after the manufacture of PVA from hydrolysis of polyvinyl acetate or oxidation during manufacturing and processing [44]. 
Differential Scanning Calorimeter (DSC) provides information about thermal changes that do not involve a change in sample mass change in sample mass. Now it is a more commonly used technique than TGA. The results of the thermal behavior of PVA and starch with glycerol and citric acid, was shown in Figure 7. From the DSC curve, the melting point $\left(\mathrm{T}_{\mathrm{m}}\right)$ of PVA blend without starch was found $198{ }^{\circ} \mathrm{C}$, and the melting point for PVA/S 5\%, PVA/S 20\%, PVA/S 40\% were found $141{ }^{\circ} \mathrm{C}, 137{ }^{\circ} \mathrm{C}$ and $131{ }^{\circ} \mathrm{C}$ respectively.

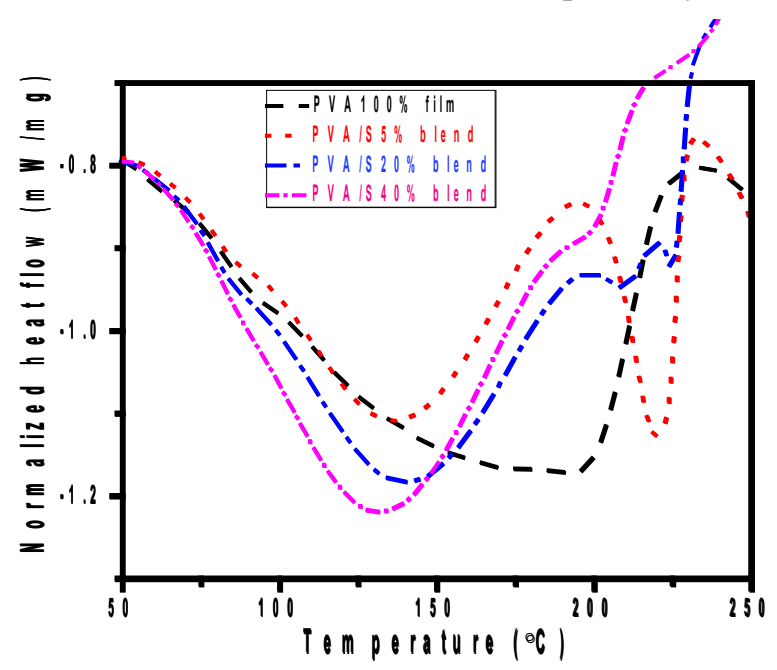

Figure 7: DSC curve of PVA/starch blends with glycerol and citric acid.

The observed $T_{m}$ is lower than that of reported one which is $230{ }^{\circ} \mathrm{C}$ for pure PVA. This is because the PVA film had already contained some water as the plasticizer. When glycerol was added, the $\mathrm{T}_{\mathrm{m}}$ decreased. The reduction in $\mathrm{T}_{\mathrm{m}}$ was attributed to the reduction in the cohesive forces of attraction between the polymer chains. The plasticizer molecules penetrated the polymer matrix because they were smaller than the polymer molecule. As a result, polar attractive forces were established between the plasticizer and chain segments, which were responsible for the reduction of the cohesive forces and, therefore, a reduction of $\mathrm{T}_{\mathrm{m}}$. Shi et al. and Shreedhar et al. also reported the decreased of $\mathrm{T}_{\mathrm{m}}$ in their work [23].

The biodegradation result showed that the buried blends were found completely degraded after taken out from the vase. So the calculation of weight loss couldn't perform. There is the various possible reason behind the degradation. Lucas et al. mentioned that in the process of biodegradation, the resistance and durability of polymeric materials are made weak by the action of microorganisms or/and environmental abiotic factors. Another suitable possible reason was given by Bonhomme et al. and Leja et al. according to them, the growth of microorganisms adhering to the polymer surface can provoke the formation of cracks, increase the size of pores and others defects, that may lead to the disintegration of a material into small fragments [45].

\section{Conclusion}

Starch was successfully extracted from locally cultivated tubers' potatoes (Solanum tuberosum). It is white, an amorphous in nature, tasteless, odorless, insoluble in cold water, alcohol, and ether. The preliminary results indicate the quality of extracted starch is good and they are as reliable as commercial starch. The FTIR peak at $2919 \mathrm{~cm}^{-1}$ indicates the presence of amylose and amylopectin. Morphology of starch shows, smooth granule, oval and ellipsoid in shape of 5-35 $\mu \mathrm{m}$ in size.

The film of starch and PVA was successfully fabricated by solution casting methods with the use of glycerol as a plasticizer and citric acid as the crosslinking agent. The fabricated blends were transparent, flexible and smooth. The blend was physically bonded. The plasticizer and crosslinking agent help blend to increase flexibility. The physically bonded blend is easily affected by moisture, temperature and air. $-\mathrm{OH}$ groups on starch and PVA formed hydrogen bonding interactions, which could improve the compatibility of the two components. As compared to pure polyvinyl, the melting point of the blend was decreased and the blend was found degradable in nature.

\section{Acknowledgements}

I am very much thankful to the National Potato Research Project (NPRP) of Nepal Agricultural Research Council (NARC), Khumaltar, Lalitpur, Nepal for their assistance with the collection of samples. I would like to express my sincere thanks to Dr. Khaga Raj Sharma (Central Department of Chemistry, Tribhuvan University, Kirtipur, Nepal for his assistance with FTIR. I would like to express my gratitude to Associate Professor Dr. Mirsolav Slouf (Institute of Macromolecular Chemistry, Czech Academy of Sciences, Czech Republic) and Dr. Jakub Sirc, (Institute of Polymer Networks and Gels, Czech Republic) for their great help in scanning electron microscope (SEM). I am greatly thankful to Dr. Vimal 
Katiyar and Ms. Neha Mulchandani (Indian Institute of Technology, Guwahati, India) for the Differential Scanning Calorimetry (DSC). I would also like to acknowledge Dr. Rajesh Pandit, Department of Chemistry, Tri-Chandra Multiple Campus, Kathmandu for the data interpretation of DSC.

\section{References}

1. B. Ghanbarzadeh, H. Almasi and A. A. Entezami, Improving the barrier and mechanical properties of corn starch-based edible films: Effect of citric acid and carboxymethyl cellulose, Industrial Crops and Products, 2011, 33, 229-235. (DOI: org/10.1016/j.indcrop.2010.10.016).

2. X. Tang and S. Alavi, Recent advances in starch, polyvinyl alcohol based polymer blends, nanocomposites and their biodegradability, Carbohydrate Polymer, 2011, 85, 7-16. (DOI: org/10.1016/j.carbpol.2011.01.030).

3. H. Tian, J. Yan, A. V. Rajulu, A. Xiang and $\mathrm{X}$. Luo, Fabrication and properties of polyvinyl alcohol/starch blend films: Effect of composition and humidity, Journal of Biological Macromolecules, 2017, 96, 518-523. (DOI: 10.1016/j.ijbiomac.2016.12.067).

4. Z. Zhu and W. Guo, Frequency, moisture content, and temperature dependent dielectric properties of potato starch related to drying with radiofrequency/microwave energy, Scientific Reports, 2017, 17, 1-11. (DOI:10.1038/s41598-01709197-y).

5. C. Menzel, E. Olsson, T. S. Plivelic, R. Andersson, C. Johansson, R. Kuktaite, L. Jarnstrom and K. Koch, Molecular structure of citric acid cross-linked starch films, Carbohydrate Polymer, 2013, 96, 270-276. (DOI: 10.1016/j. carbpol.2013.03.044).

6. P. A. Sreekumar, M. A. Al-Harthi and S. K. De, Effect of glycerol on thermal and mechanical properties of polyvinyl alcohol/starch blends, Journal of Applied Polymer Science, 2012, 123(1): 135-142. (DOI: 10.1002/app.34465).

7. R. Nagarkar and J. Patel, Polyvinyl alcohol: A comprehensive study, Acta Scientific Pharmaceutical Sciences, 2019, 3(4), 34-44.

8. L. T. Sin, W. A Rahman, A. R. Rahmat and
A. A. Samad, Computational modeling and experimental infrared spectroscopy of hydrogen bonding interactions in polyvinyl alcohol-starch blends, Journal of Polymer, 2010, 51, 1206-1211. (DOI: 10.1016/j.polymer.2010.01.021).

9. L. J. Mao, S. Imam, S. Gordon, P. Cinelli and E. Chiellini, Extruded cornstarch-glycerolpolyvinyl alcohol blends: mechanical properties, morphology, and biodegradability, Journal of Polymers and the Environment, 2000, 8(4), 205211.

10. F. W. Bai, W. A. Anderson and M. Moo-Young, Research review paper: Ethanol fermentation technologies from sugar and starch feed stocks, Biotechnology Advances, 2008, 26, 89- 105. (DOI: 10.1016/j.biotechadv.2007.09.002).

11. L. Jamai, K. Ettayebi, E. J. Yamani and M. Ettayebi, Production of ethanol from starch by free and immobilized Candida tropicalis in the presence of $\alpha$-amylase, Bioresource Technology, 2007, 98(14), 2765-2770. (DOI: 10.1016/j. biortech.2006.09.057).

12. K. Tadasa and K. Takeda, Anaerobic digestion of raw starch by Bacillus species, Journal of Fermentation Technology, 1986, 64(1), 81-85. (DOI: 10.1016/0385-6380(86)90062-2).

13. H. Yang and J. Shen, Effect of ferrous iron concentration on anaerobic bio-hydrogen production from soluble starch, International Journal of Hydrogen Energy, 2006, 31(15), 21372146. (DOI: 10.1016/j.ijhydene.2006.02.00).

14. T. Amon, B. Amson, V. Karyvoruchko, A. Machmuller, K. Hopfner-Sixt and V. Bodiroza, W. Zollitsch, Methane production through anaerobic digestion of various energy crops grown in sustainable crop rotations, Bioresource Technology, 2007, 98(17), 3204-3212. (DOI: 10.1016/j.biortech.2006.07.007).

15. E. Grinzato, G. Cadelano and P. Bison, Moisture map by IR thermography, Journal of Modern Optics, 2010, 57, 1770-1778. (DOI: 10.1080/09500341003731597).

16. E. Chiellini, A.Corti and R. Solaro, Biodegradation of poly(vinyl alcohol) based blown films under different environmental conditions, Polymer Degradation and Stability, 1999, 64, 305-312. 
(DOI: 10.1016/S0141-3910(98)00206-7).

17. L. Chen, S. H. Iman, T. M. Stein, S. H. Gordon, C. T. Hou and R. V. Greene, Starch-polyvinyl alcohol cast film-performance and biodegradation, Polymer Preprints, 1997, 37, 461-462.

18. M. A. Russo, C. O'Sullivan, B. Rounsefell, P. J. Halley, R. Truss and W. P. Clarke, The anaerobic degradability of thermoplastic starch: Polyvinyl alcohol blends: Potential biodegradable food packaging materials, Bioresource Technology, 2009, 100, 1705-1710. (DOI: 10.1016/j. biortech.2008.09.026).

19. W. L. Chai, J. D. Chow, C. C. Chen, F. S. Chuang and W. C. Lu, Evolution of biodegradability polyvinylalcohol/starch blends: A methodological comparison of environmentally friendly materials, Journal of the Polymers and the Environment, 2009, 17, 71-82. (DOI: 10.1007/s10924-0090123-1).

20. P. Cinelli, E. Chiellini, S. H. Gordon and S. H. Imam, Characteristics and degradation of hybrid composite films prepared from PVA, starch and lignocellulosics, Macromolecular Symposia, 2003, 197, 143-155. (DOI: 10.1002/ masy.200350714).

21. S. Tang, P. Zou, H. Xiong and H. Tang, Effect of nano- $\mathrm{SiO}_{2}$ on the performance of starch/ polyvinyl alcohol blend films, Carbohydrate Polymers, 2008, 72, 521-526. (DOI: 10.1016/j. carbpol.2007.09.019).

22. M. C. Pascu, M. C. Popescu and C. Vasile, Surface modification of some nanocomposites containing starch, Journal of Physics D: Applied Physics, 2008, 41, 1-12. (DOI: 10.1088/00223727/41/17/175407/meta).

23. R. Shi, J. Bi, Z. Zhang, A. Zhu, D. Chen, X. Zhou, L. Zhang and W. Tian, Ageing of soft thermoplastic starch with high glycerol content, Carbohydrate Polymer, 2008, 72, 763-770. (DOI: 10.1002/app.25193).

24. M. M. Hashem, W. Kesting, A. A. Hebeish, N. Y. Abou-Zeid and E. Schollmeyer, Characterization and application of poly(vinyl alcohol)/starch composite as a sizing agent, Die Angewandte Makromolekularechemie, 1996, 241, 149-163. (DOI: 10.1002/apmc.1996.052410112).
25. O. Vilpoux and L. Avérous. Starch-based plastics. In M. P. Cereda, and O. Vilpoux (Eds.), Technology, use and potentialities of Latin American starchy tubers, NGO Raizes and Cargill Foundation, São Paolo - Brazil, 2004, 18, 521-553.

26. J. Singh and N. Singh, Studies on the morphological, thermal and rheological properties of starch separated from some Indian potato cultivars, Food Chemistry, 2001, 75, 6777. (DOI: 10.1016/S0308-8146(01)00189-3).

27. AOAC, Official Methods of Analysis, Association of official analytical chemist (AOAC), Washington, DC, 2000.

28. N. A. Azahari, N. Ohtman and H. Ismail, Biodegradation studies of poly(vinylalcohol)/ corn starch blend films in solid and solution media, Journal of Physiological Science, 2011, 22, 15-31.

29. A. N. Jyothi, K. S. Kiran, B. Wilson, S. N. Moorthy and B. Nambisan, Wet storage of cassava starch: use of sodium metabisulphite and acetic acid and the effect on starch properties, StarchStärke, 2007, 59, 141-148. (DOI: 10.1002/ star.200600583).

30. I. R. M. Benesi, M. T. Labuschagne, A. G. O. Dixon and N. M. Mahungu, Stability of native starch quality parameters, starch extraction and root dry matter of cassava genotypes in different environments, Journal of the Science of Food and Agriculture, 2004, 84, 1381-1388. (DOI: 10.1002/jsfa.1734).

31. R. Joseph, H. H. Yeoh and C. S. Loh, Induced mutations in cassava using somatic embryos and the identification of mutant plants with altered starch yield and composition, Plant Cell Reports, 2004, 23, 91-98. (DOI: 10.1007/s00299-0040798-7).

32. V. Olomo and O. Ajibola, Processing factors affecting the yield and physicochemical properties of starch from cassava chips and flour, StarchStärke, 2003, 55, 476-481. (DOI: 10.1002/ star.200300201).

33. I. R. M. Benesi, M. T. Labuschagne, L. Herselman, N. M. Mahungu and J. K. Saka, The effect of genotype, location and season on cassava starch 
extraction, Euphytica, 2008, 160, 59-74. (DOI: 10.1007/s10681-007-9589-x).

34. A. T. Osunsami, J. O Akingbala and G. B. Oguntimein, Effect of storage on starch content and modification of cassava starch, StarchStärke, 1989, 41, 54-57. (DOI: 10.1002/ star.19890410205).

35. F. Meuser, H. D. Smolnik, C. Rajani and H. G. Giesemann, Comparison of starch extraction from tapioca chips, pellets and roots, StarchStärke, 1978, 30, 299-306. (DOI: 10.1002/ star.19780300904).

36. J. C. Pérez, J. I. Lenis, F. Calle, N. Morante, T. Sánchez, D. Debouck and H. Ceballos, Genetic variability of root peel thickness and its influence in extractable starch from cassava (Manihot esculenta Crantz) roots, Plant Breeding, 2011, 130, 688-693. (DOI: 10.1111/j.14390523.2011.01873.x).

37. S. S. Nielsen, Food Analysis, $2^{\text {nd }}$ Ed. Aspon Publication, Maryland, 1998, 40-250.

38. E. Nuwamanya, Y. Baguna, E. Wembabazi and P. Rubaihayo, A comparative study of the physicochemical properties of starches from root, tuber and cereal crops, African Journal of Biotechnology, 2011, 10(56), 12018-12030. (DOI: 10.5897/AJB10.2310).

39. A. Uba, T. Izuagie, L. G. Hassan, M. Achor and D. M. Sahabi, Charaterization of starch isolated from Mangifera indica seeds, Nigerian Journal of Basic and Applied Science, 2011a, 19(2), 224230 .
40. R. Hoover, T. Hughes, H. J. Chung and Q. Liu, Composition, molecular structure, properties, and modification of pulse starches: A review, Food Research International, 2010, 43, 399-413. (DOI: 0.1016/j.foodres.2009.09.001).

41. K. S. Sandhu and N. Singh, Some properties of corn starches II: Physicochemical, gelatinization, retrogradation, pasting and gel textural properties, Food Chemistry, 2007, 101, 1499-1507. (DOI: 10.1016/j.foodchem.2006.01.060).

42. Y. Yuan, L. Zhang, Y. Dai and J. Yu, Physicochemical properties of starch obtained from Dioscorea nipponica Makino comparison with other tuber starches, Journal of Food Engineering, 2007, 82, 436-442. (DOI: 10.1016/j. jfoodeng.2007.02.055).

43. A. H. D. Abdullah, S. Chalimah, I. Primadona and M. H. G. Hanantyo, Physical and chemical properties of corn, cassava, and potato starchs, Earth Environmental Science, 2018, 160, 012003. (DOI: 10.1088/1755-1315/160/1/012003).

44. J. Wang, K. Guo, X. Fan, G. Feng and C. Wei, Physicochemical properties of C-type starch from root tuber of Apios fortunei in comparison with maize, potato, and pea starches, Molecules, 2018, 23, 2132. (DOI: 10.3390/molecules23092132).

45. S. Pokhrel, R. Adhikari and P. N. Yadav, Fabrication and characterization of biodegradable poly(vinyl alcohol)/chitosan blends, Asian Journal of Chemistry, 2017, 29, 1602-1606. (DOI: 10.14233/ajchem.2017.20612). 